\title{
Funding delays handicap ISABELLE in race for new particle
}

The US Department of Energy has extended construction time for Brookhaven's $400 \times 400 \mathrm{GeV}$ accelerator from five to seven years. David Dickson reports on the implications.

Physicists at the Brookhaven National Laboratory on New York's Long Island are trying to persuade the Department of Energy to reverse its decision to extend the construction period of its new $400 \times 400 \mathrm{GeV}$ intersecting storage accelerator (ISABELLE).

At stake is a race with the European Organisation for Nuclear Research (CERN) in Geneva to demonstrate the existence of the theoretically predicted intermediate vector boson, known as the $W$ particle. According to the Weinberg-Salam unification theory, this particle carries the weak force in the same way that the photon carries the electromagnetic force.

Initially, Brookhaven's scientists hoped ISABELLE's larger number of interactions would compensate for CERN's planned earlier start in the search for the particle using protonantiproton interactions. The extra two years' delay in construction could, it is feared, considerably reduce chances of being first past the post.

Construction work on what has been described as the largest basic research project ever built began last month. When completed, the $2 \frac{1}{2}$-mile circumference accelerator will provide a range of detection facilities for studying the results of collisions between two beams of opposite circulating protons.

The Department of Energy, under pressure from members of Congress, agreed last year to put $\$ 23$ million to begin construction work on ISABELLE into its budget request for 1979; when this money officially became available last month, a ground-breaking ceremony took place.

However, in an attempt to keep the lid on funding for high energy physics over the next few years, the department later announced that the accelerator's construction schedule would be increased from five years to seven. The first experiments have been pushed back from 1984 to 1986.

ISABELLE has been designed to make use of pulses of $30 \mathrm{GeV}$ protons from the Alternating Gradient Synchroton, Brookhaven's last major high energy physics facility which came into operation in 1961. The pulses will be stacked sequentially in each ring until 10 amps of circulating current has been built up, at which time the two beams can be slowly accelerated to full energy and made to interact at six separate experimental stations.
The proton collisions will provide a centre-of-mass energy of $800 \mathrm{GeV}$, equivalent to that available from protons of $340,000 \mathrm{GeV}$ striking protons at rest. ISABELLE will therefore be able to extend by a factor of 10 the centre-of-mass energy range presently available on CERN's Intersecting Storage Ring; it will also have a far greater luminosity (the factor which determines the number of interactions).

ISABELLE has been on the drawing board since 1971, when preliminary designs were first made, and has enjoyed the consistent backing of the US high energy physics community. Official procrastination was broken last year by Representative Jerome Ambro, a Long Island congressman with one eye on science and the other on the jobs and money ISABELLE will bring.

After some political horse-trading that also involved the decision to site the Solar Energy Research Institute in Denver, Colorado, $\mathrm{Mr}$ Ambro persuaded Congress to add $\$ 5$ million to the Department of Energy's authorisation for 1978 to go ahead with ISABELLE-and to defeat attempts by the Office of Management and Budget to have the money deferred.

Further problems were raised when Dr Robert R. Wilson, director of Fermilab, tried to outhid Brookhaven for a major share of the 1979 budget in order to speed up the construction of Fermilab's Energy Doubler. However Wilson's hand was weakened when the department's High Energy Physics Advisory Panel reconfirmed top priority for ISABEI.LE.

The final hurdle came late in the spring, when the department announced that it had decided to maintain funding for high energy physics at a constant in action at the ground-breaking ceremony level over the next few years - and that ISABELLE's construction period was to be extended to avoid initial "peaking" that would upset this scheme.

In political terms, the department hopes this will make the high energy physics programme more acceptable to a cost-conscious Congress. However, economically, the result has been to increase the projected overall cost of ISABELLE from $\$ 240$ million to $\$ 275$ million; and scientifically it means the extra two-year delay until the first results are produced.

"We would not have built this machine just to discover the W particle," Dr Jim Sandford, project manager for ISABELLE said last week. $\mathrm{He}$ points out, for example, that the increased luminosity over CERN's SPS ring, means that Brookhaven will be in a much better position for a detailed analysis of higher energy states, decay modes and so on.

"But I do not want to miss out, if at all possible, in finding it. With our greater luminosity, we had a good chance of finding the particle ahead of CERN on the five-year schedule. On a seven-year schedule, we have considerably less chance."

Brookhaven scientists still hope that, once construction of the accelerator's superconducting magnets and other components is well under way, the Department of Energy can be persuaded to alter its policy and make more money available earlier-saving on costs by reducing labour and avoiding some of the effects of inflation.

So far, the department has remained firm. It has proposed to make available $\$ 45$ million for ISABELLE's construction costs in the fiscal year 1980 , making the total for the first two years still considerably less than the $\$ 80$ million which the laboratory had proposed for the first year of construction alone.

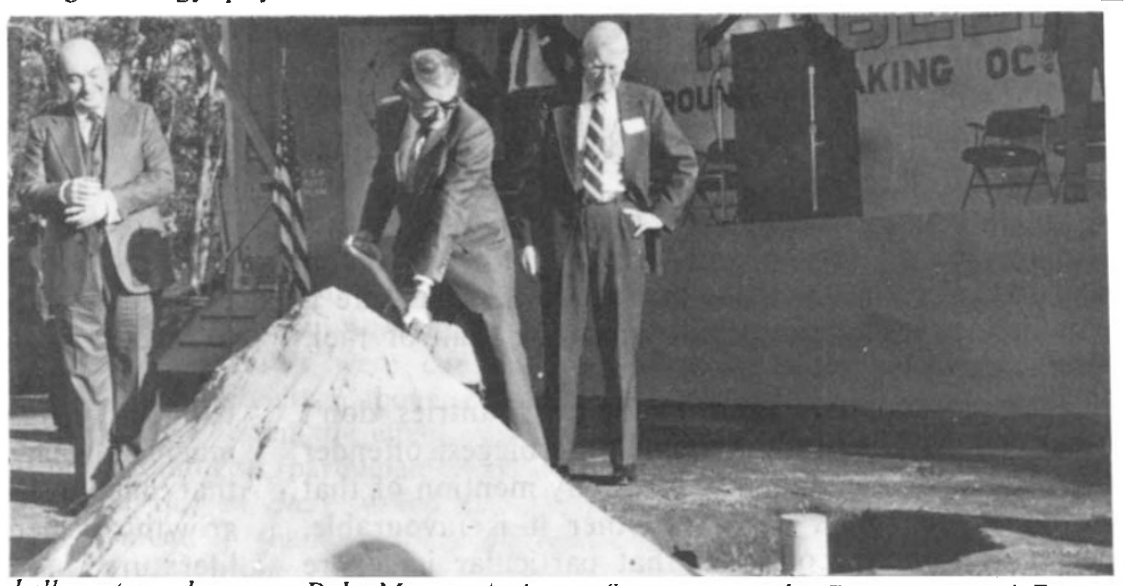

Isabelle gets under way: Dale Myers, Assistant Secretary at the Department of Energy, 